\title{
Imigração e educação nos relatórios dos presidentes da Província do Paraná
}

\author{
Immigration and education in the reports of the presidents \\ of the Province of Paraná
}

\author{
La inmigración y la educación en los informes de los \\ presidentes de la Provincia de Paraná
}

\section{Rodrigo Boçõen, Maria Elisabeth Blanck Miguel*}

\section{Resumo}

O presente texto busca discutir a forma como educação e imigração, especialmente de poloneses, era tratada pelos governantes da Província do Paraná, por meio da análise dos Relatórios dos Presidentes da Província, abrangendo o período de 1871, o início da imigração polonesa ao Paraná, e 1889, o fim do regime monárquico no Brasil. Para a construção deste trabalho, foi fundamental a consulta a autores como Lilian A. Wachowicz (1984), Ruy

RB: Mestre em Educação, e-mail: rbocoen@yahoo.com.br

MEBM: Doutora em História e Filosofia da Educação, e-mail: maria.elisabeth@pucpr.br 
C. Wachowicz (2010), Saviani (2007), Faria Filho (1998) Miguel (1997) e Vieira (2011), além de outras fontes primárias, como a legislação educacional em vigor no período. Com a realização dessa pesquisa, foi possível observar o planejamento da imigração para a Província, os principais problemas reconhecidos na Instrução Pública do período, além das medidas tomadas ou planejadas para a melhoria do ensino entre os imigrantes.

Palavras-chave: Imigração. Educação. Legislação do Ensino.

\section{Abstract}

The following text aims to discuss how education and immigration, especially of polish immigrants, were treated by the governors of the Province of Parana, by analyzing the Reports of the Presidents of the Province, covering the period between 1871, when the polish immigration to Parana has begun, and 1889, when the monarchy in Brazil has ended. To make this study, the access to authors like Lilian A. Wachowicz (1984), Ruy C. Wachowicz (2010), Saviani (2007), Faria Filho (1998) Miguel (1997) and Vieira (2011) were essential, besides other primary sources, as the current educational legislation in the period. With the accomplishment of this research, it was possible to observe the immigration planning to the Province, the main problems recognized in the Public Instruction of the period, besides the actions taken or planned to the improvement of the public instruction among the immigrants.

Keywords: Immigration. Education. Educational legis/ation.

\section{Resumen}

En este trabajo se discute la forma como la educación y la inmigración, especialmente de los inmigrantes polacos, fue tratada por los gobernantes de la provincia de Paraná, mediante el análisis de los Informes de los Presidentes de la Provincia de Paraná, que abarca el período comprendido entre 1871, el comienzo de la inmigración polaca en Paraná, y 1889, el fin de la monarquía en Brasil. Para la construcción de este trabajo fue esencial consultar a los autores como Lilian A. Wachowicz (1984), Ruy C. Wachowicz (2010), Saviani (2007), Faria Filho (1998), Miguel (1997), Vieira (2011), y otras fuentes primarias, como la legislación educativa en el periodo. Con este estudio, se observó la planificación de la inmigración en la provincia, los principales problemas reconocidos en la Instrucción Pública de la época, además de las medidas adoptadas o previstas para la mejora de la educación entre los inmigrantes.

Palabras clave: Inmigración. Educación. Legislación sobre la enseñanza. 


\section{Introdução}

Este texto tem o objetivo de discutir a forma como as questões relativas à imigração européia, especialmente a polonesa e a educação eram tratadas, e em que medida estavam relacionadas na visão dos governantes da Província do Paraná. Para tanto, se procede à análise dos Relatórios dos Presidentes da Província, no período compreendido entre 1871 e 1889, datas que marcam, respectivamente, o início da imigração polonesa para esse Estado e o fim do regime monárquico no Brasil.

Os Relatórios dos Presidentes da Província do Paraná, doravante denominados apenas Relatórios, constituem-se um importante tipo de documento oficial do período provincial, tendo em vista a facilidade de sua consulta, já que estão disponíveis no site do Arquivo Público do Paraná, e a diversidade dos assuntos de que tratam. O site do Arquivo Público do Paraná explica que os Relatórios de Governo eram elaborados para atender a exigência contida em um Aviso Circular Imperial, do ano de 1848. Segundo este documento, todo ocupante do cargo de presidente da Província tinha o dever de, no início de cada ano, apresentar à Assembleia provincial uma mensagem ou exposição prestando contas da situação da Província no ano anterior (ARQUIVO PÚBLICO DO PARANÁ, 2010).

Dentre os assuntos abordados nos Relatórios, a colonização da Província tinha grande destaque, descrevendo a situação das numerosas colônias criadas pelo governo provincial e fornecendo informações relativas ao investimento financeiro, movimento populacional, infraestrutura, dentre outros. Ainda, a questão da Instrução Pública era abordada nos Relatórios, sendo possível encontrar quadros estatísticos registrando o número de alunos, professores e escolas de toda a Província.

O presente trabalho abordará, portanto, uma questão relacionada a esses dois temas. Uma vez os imigrantes estabelecidos em suas colônias, novas necessidades surgem para esses grupos, sendo a educação uma delas. Assim, busca-se descobrir se tal necessidade chegava ao conhecimento dos governantes da Província do Paraná, e de que forma se pretendia atender às demandas dos grupos recém-chegados. 
Tendo em vista essas questões, será fundamental a consulta a autores que possam fornecer uma base teórica em que a presente pesquisa possa se apoiar, como Ruy C. Wachowicz (2010), Miguel (1997), Azevedo (1996) e Saviani (2007), que dão contribuições sobre o período abordado e aos temas relacionados. Além disso, será necessária a consulta a outras fontes primárias, além dos Relatórios, especialmente a legislação educacional do período, que pode ser consultada em Miguel (2000).

Este artigo está organizado em três subtítulos. No primeiro, fazem-se algumas considerações sobre o uso de fontes oficiais e de fontes digitalizadas na pesquisa em História da Educação. No segundo, tratam-se alguns aspectos relativos à imigração na Província do Paraná e sua abordagem nos Relatórios, focalizando a imigração polonesa. Em seguida, trata-se da questão da Instrução Pública no período e, especialmente, da Instrução voltada às comunidades imigrantes.

\section{Fontes digitalizadas e documentos oficiais}

Ao estudar temas relacionados à História da Educação, a análise da legislação de determinado período pode ser uma ferramenta muito útil para a compreensão de práticas e ideias então em vigor. Segundo Azevedo (1996, p. 561): "[...] um dos mais preciosos documentos para o estudo da evolução de uma sociedade e do caráter de uma civilização se encontra na legislação escolar, nos planos e programas de ensino e no conjunto de instituições educativas [...]". Tal afirmação: "[...] anima os pesquisadores a debruçarem-se sobre as leis educacionais na tentativa de melhor compreenderem o desenvolvimento histórico da educação brasileira" (MIGUEL, 1997, p. 676).

Faria Filho (1998, p. 94) lembra que, mesmo que nem sempre um pesquisador trabalhe diretamente com a legislação, não se pode afirmar que esteja trabalhando fora de seu raio de influência. E os Relatórios exemplificariam essa afirmação, já que todos têm origem em algum ato legal, como é possível observar na própria redação dos mesmos: 
"Cumprindo o dever que me impõe o aviso circular de 11 de agosto de 1848, apresento a V. Ex. a exposição dos negócios públicos da província [...]" (LEÃO, 1870, p. 1); "Dando cumprimento ao preceito constitucional de expor-vos as necessidades da província, que dignamente representaes [...]" (LISBOA, 1871, p. 1).

Assim, ainda segundo Faria Filho (1998, p. 94-95), "todos os relatórios e quase a totalidade dos demais textos oriundos da administração pública estadual [...], são produzidos em obediência à legislação em vigor, ou, em outros casos, representam a própria legislação".

A análise da legislação, conforme Miguel (1997, p. 676), deve levar em consideração que a mesma "traduz o resultado do jogo de forças sociais que acontecem nos planos econômico-político e cultural, nos quais a educação sistemática se insere".

Em geral, o acesso a tal documentação é intermediado pelos arquivos. Segundo Vieira (2011, p. 1632), "os arquivos realizam o trabalho de coletar, tratar, recuperar, organizar e colocar a memória de uma região à disposição da sociedade”. As dificuldades em conciliar a preservação de documentos e disponibilizá-los ao acesso do público têm sido amenizadas, em grande medida, pelo desenvolvimento da tecnologia. Ainda conforme Vieira (2011, p. 1633-1634):

[...] a tecnologia, neste particular, tem se tornado aliada da pesquisa em história, seja pela microfilmagem/digitalização dos documentos mais antigos ou pela organização e catalogação do material que facilitam e tornam mais simples o acesso. O armazenamento eletrônico se traduz em praticidade e economia de tempo e espaço, garantindo a preservação dos documentos originais e evitando seu manuseio constante pelos pesquisadores.

Apesar da mudança na forma de acesso, não se altera o trabalho com o conteúdo dos documentos, que exige do pesquisador "a mesma minúcia e paciência na leitura, na análise e na interpretação do conteúdo dos documentos que as necessárias na consulta aos arquivos tradicionais" (VIEIRA, 2011, p. 1635). 


\section{Imigração}

A imigração europeia para o Paraná inscreve-se num amplo projeto de colonização levado a efeito pelo governo brasileiro desde a chegada de D. João VI em 1808, e que teve continuidade no período imperial, após a independência do país. Com a vinda de imigrantes europeus ao Brasil, buscava-se a criação de uma classe intermediária na estrutura social do país, independente dos grandes senhores latifundiários, o estímulo à policultura, em oposição às monoculturas canavieira e cafeeira, além de uma solução à questão dos vazios demográficos e da substituição da mão-de-obra escrava (OBERACKER JR. In: HOLANDA, 2004, p. 260; KERSTEN, 1983, p. 37-38).

Nessa perspectiva é fundada, em 1819, a colônia de Nova Friburgo, "a primeira colônia que correspondia perfeitamente ao novo tipo de colonização, formada de colonos estrangeiros, 1.600 suíços de língua francesa e confissão católica" (OBERACKER JR. In: HOLANDA, 2004, p. 262). Mais tarde, novas colônias são formadas ao longo do caminho para as fronteiras do sul do país, como Santo Amaro e Itapecerica, em São Paulo, em 1829, Rio Negro, na posterior fronteira entre Paraná e Santa Catarina, também em 1829, e São Leopoldo, no Rio Grande do Sul, esta em 1824 (OBERACKER JR. In: HOLANDA, 2004, p. 264).

A colônia de Rio Negro, fundada com 238 imigrantes alemães, aos quais se acrescenta uma nova leva de 100, em 1833, "foi a primeira tentativa concreta para estabelecer imigrantes europeus não portugueses em território paranaense" (WACHOWICZ, R. C., 2010, p. 174). Em 1847, graças aos esforços do tropeiro João da Silva Machado, futuro Barão de Antonina, e do filantropo suíço João Maurício Faivre, é fundada às margens do rio Ivaí, com 87 imigrantes franceses, a colônia Teresa. Entretanto, os resultados dessa colônia não se mostraram satisfatórios. Em 1852, outro suíço, Carlos Perret Gentil, fundou na entrada da Baía de Paranaguá, a colônia de Superagui, composta por 35 imigrantes suiços e alemães e também um bom número de nacionais. Essa colônia também não prosperou, embora não tenha desaparecido completamente (WACHOWICZ, R. C., 2010, p. 174). 
Em 1859, é criada a colônia de Assungui, localizada a 109 quilômetros ao norte de Curitiba e planejada como uma grande colônia agrícola em regime de pequena propriedade, que abasteceria as cidades com alimentos e faria o Paraná equiparar-se com a vizinha província de Santa Catarina, que à época contava com dois núcleos coloniais de grande sucesso: Blumenau e Dona Francisca (Joinville). A falta de infraestrutura adequada, sem estradas razoáveis para o escoamento da produção, leva ao fracasso da colônia, com um grande número de imigrantes abandonando suas propriedades (WACHOWICZ, R. C., 2010, p. 175-176).

\section{A política imigratória de Lamenha Lins}

Quando chegam ao Paraná os primeiros imigrantes poloneses, no ano de 1871, a forma como era planejada a colonização na Província encontrava-se em processo de transformação, como se pode observar nos Relatórios do final da década de 1860.

No relatório apresentado em 15/03/1867, o presidente Cezar Burlamaque estipula algumas condições para a instalação de imigrantes na província. Segundo o documento, o governo obriga-se, primeiramente, a obter terrenos para os imigrantes nos subúrbios de Curitiba. Os imigrantes receberiam também uma casa provisória, várias espécies de sementes e os instrumentos agrícolas que houvesse em Curitiba. Tais gastos seriam pagos pelos imigrantes ao governo dentro de um prazo de 5 anos, em três parcelas, sendo que as benfeitorias construídas nos terrenos ficariam hipotecadas até o pagamento da dívida total. O governo forneceria, ainda, uma diária de 800 réis nos primeiros 6 meses de estadia dos colonos em seus lotes. O pagamento, segundo consta do Relatório, seria suspenso caso os imigrantes "não se entregarem assiduamente ao trabalho, logo que lhes forem designados os respectivos lotes" (BURLAMAQUE, 1867, p. 65).

O estabelecimento de imigrantes nas proximidades de Curitiba consta novamente do Relatório apresentado em 24 de dezembro de 1870 
pelo vice-presidente da Província, Agostinho Ermelino de Leão, ao presidente Venâncio José de Oliveira Lisboa. No documento, Ermelino de Leão relata:

[...] os emigrantes Leopoldo Recher Himdrich Pesk, Ernest Kaener e João Henrique Egilbard apresentaram-se-me manifestando o desejo de estabelecerem-se no lugar denominado - Pilarzinho - nas immediações desta capital.

Considerando o estado próspero em que se acha o núcleo de população allemã, que se estende em todo o rocio, e as vantagens colhidas da agricultura e indústria pelos colonos espontâneos alli estabelecidos sem o menor dispêndio dos cofres do Estado, não duvidei em atender o pedido daqueles emigrantes e expedi ordem ao delegado das terras para escolher os lotes que lhes conviessem, devendo elles requerer a concessão à câmara municipal e a despeza ser paga pela tesouraria de fazenda.

Cerca de 200 allemães chegados à colônia D. Francisca preferiram estabelecer-se nos mesmos terrenos (LEÃO, 1870, p. 20).

A vinda dos primeiros imigrantes poloneses ao Paraná é conteúdo do Relatório apresentado pelo presidente Venâncio Lisboa, em 15 de fevereiro de 1872. No subtítulo "Colonização Polaca” encontra-se o relato da chegada de 78 imigrantes poloneses ${ }^{1}$, estabelecidos anteriormente em Santa Catarina. Estes imigrantes foram instalados na região do Pilarzinho e empregados nos trabalhos das obras públicas, onde receberiam salário para suas necessidades iniciais (LISBOA, 1872, p. 64).

Em 1873, durante a administração do presidente Frederico Abranches, outros 258 poloneses chegam ao Paraná, sendo instalados em uma área no Ahú, ao norte de Curitiba, onde surge a colônia Abranches (GLUCHOWSKI, 2005, p. 30).

Em maio de 1875, Adolpho Lamenha Lins assume a presidência da Província do Paraná, tendo entre seus principais objetivos promover

1 Outros autores afirmam que o grupo inicial de imigrantes poloneses era de 164 pessoas, como é o caso de Gluchowski (2005, p. 30). 
a imigração europeia. Para tanto, estudou o problema do fracasso da colônia Assungui, examinou o comportamento dos reimigrantes alemães, que vinham espontaneamente de Joinville e estabeleciam-se em chácaras ao redor de Curitiba, além de avaliar o funcionamento de colônias como Pilarzinho e Abranches (WACHOWICZ, R. C., 2010, p. 176-177).

Com base nessas informações, Lamenha Lins:

[...] desenvolveu um plano fundamentado no sentido de criar no primeiro planalto paranaense uma sociedade camponesa em moldes ainda não existentes no Brasil [...], no sentido do estabelecimento de milhares de aldeões europeus em propriedade subdividida, isto é, fixa-los à terra como legítimos proprietários" (WACHOWICZ, R. C., 1977, p. 9).

Em seu relatório de 15/02/1876, Lamenha Lins afirma que se deve dizer a verdade aos imigrantes sobre a nova terra, sem descrições poéticas e promessas exageradas. Ressalta, ainda, a importância de facilitar o transporte dos imigrantes, distribuírem-lhes bons lotes de terras, nas proximidades dos centros urbanos e das estradas de rodagem, dando-lhes o direito de propriedade e, depois de bem estabelecidos, livrá-los da tutela governamental (LINS, 1876, p. 79).

Um ano depois, em seu relatório de 15/02/1877, Lamenha Lins descreve de forma mais detalhada o processo de estabelecimento dos imigrantes nas colônias:

[...] medidos e demarcados lotes de terras de cultura nos arredores da cidade, traçadas as estradas, entrega-se um lote a cada família, com uma casa provisória, regularmente construída.

Ao colono maior de dez annos dá-se como auxílio de estabelecimento $20 \$ 000$.

Cada família recebe mais $20 \$ 000$ para compra de utensílios e sementes. Logo que o colono se estabelece é empregado na construcção das estradas do núcleo recebendo a ferramenta necessária e cessa então a alimentação por conta do governo.

Em cada núcleo funda-se uma escola e edifica-se uma capella, com excepção daquelles que por muito próximos da cidade dispensam essa construcção. 
Além do trabalho nas estradas do núcleo, encontra o colono serviço nas obras públicas geraes.

Estabelecidos por esta forma, ficam os colonos entregues a sua própria iniciativa e somente obrigados a pagar no prazo do regulamento de 1867, a sua dívida ao governo.

Esta dívida, pelo que respeita aos gastos feitos desde que o colono chega a esta província, ainda não excedeu a $500 \$ 000$ por cada família de 5 pessoas, termo médio, incluindo o preço das terras, e está garantida pelo valor real do lote, casa e accessórios.

Achando na cidade prompto mercado para o producto de sua lavoura e fácil consumo de lenha, hortaliças, e productos de pequenas indústrias, o colono pode em tempo breve libertar-se dessa dívida para com o Estado e habilitar-se a desenvolver a sua lavoura (LINS, 1877, p. 80).

Lamenha Lins ainda demonstrava uma grande preocupação em oferecer certa estrutura no momento da instalação das colônias, como a construção de estradas, casas provisórias, escola e capela. Além disso, ao empregar o colono nas "obras públicas gerais", criam-se condições para que ele possa sustentar sua família até obter as primeiras colheitas em sua própria lavoura.

Por meio da aplicação de seu plano, Lamenha Lins criou os núcleos coloniais de Santa Cândida, Órleans (em 1875), Lamenha, Santo Inácio, D. Pedro, D. Augusto, Riviere e Tomás Coelho (em 1876), que receberam cerca de 3.854 imigrantes poloneses até o ano de 1889 (GLUCHOWSKI, 2005, p. 42). Mais tarde, frutos dessa mesma política imigratória, novas colônias são fundadas, como Zacarias, Inspetor Carvalho e Murici, dentre outras, onde predomina o elemento polonês.

A política imigratória de Lamenha Lins recebeu elogios, em 1886, do então presidente da Província, Alfredo D’Escragnolle Taunay. Nas palavras deste, Lamenha Lins foi:

[...] um dos mais illustres presidentes, que tem tido o Paraná [...] seguindo um plano concebido com segurança de vistas, e desenvolvido com firmeza, deixou com toda a razão a margem o falso presupposto de que convinha primeiro povoar as regiões desertas do paiz, para depois fazer refluir a população para a peripheria, quando todo o contrario 
deve ser feito, e só por iniciativa dos próprios interessados (TAUNAY, 1886, p. 49).

Na administração de Taunay, novas colônias com o predomínio de imigrantes poloneses foram criadas, como Antônio Prado, ao norte de Curitiba, Alice e Cristina, na região de Campo Largo, e Barão de Taunay, na região do atual município de Araucária.

Assim, no período de 1871 a 1889, entraram no Brasil aproximadamente 8.080 imigrantes poloneses. Deste total, cerca de 6.530, foram estabelecidos no Paraná, representando mais de $80 \%$ do total (GLUCHOWSKI, 2005, p. 45).

\section{Educação}

Em boa parte da história da educação brasileira, toda a estrutura de ensino existente pertencia ao esforço dos padres jesuítas, que possuíram, no Brasil colonial, 25 residências, 36 missões, 17 colégios e seminários, além de seminários menores e escolas de ler, escrever e contar (SODRÉ, 1999, p. 27). Toda essa estrutura entrou em derrocada com a expulsão da Companhia de Jesus dos territórios portugueses, sem a criação de uma estrutura nova em substituição, já que "[...] o desenvolvimento das aulas régias deu-se em ritmo lento, pelas resistências encontradas e pela falta de recursos financeiros" (SAVIANI, 2007, p. 107).

A reforma feita pelo Marquês de Pombal, "[...] se careceu de méritos e assinalou sua ineficiência no descalabro do ensino, na segunda metade do século XVIII, teve um traço significativo: representou o ingresso do Estado na solução do problema [...]" (SODRÉ, 1999, p. 28). Nesse sentido, Saviani (2007, p. 107) afirma que tais reformas: "[...] tinham como objetivo criar a escola útil aos fins do Estado, em substituição àquela que servia aos interesses eclesiásticos".

Entretanto, uma lei de educação em nível nacional ganharia forma apenas nos primeiros anos do Império brasileiro, com a "Lei das 
Escolas de Primeiras Letras", de 1827. Tal documento não permaneceu em vigor por muito tempo, sendo substituído pelo Ato Adicional à Constituição do Império de 1834, pelo qual o governo central transferia a incumbência de cuidar das escolas primárias e secundárias para os governos provinciais (SAVIANI, 2007, p. 129). Essa medida impediu a consolidação educacional dentro de um sistema de ensino público, subordinado a diretrizes comuns, e não deixou perspectivas para uma política educacional de larga envergadura (AZEVEDO, 1996, p. 556).

Na legislação educacional da Província do Paraná, coletada por Miguel (2000), pode-se observar que as primeiras leis elaboradas pelos governos da Província do Paraná, após sua emancipação política em 19 de dezembro de 1853, tratam, em sua maioria, da criação e extinção de cadeiras nas principais localidades, incluindo as colônias de imigrantes existentes. É em 1857 que surge o primeiro Regulamento de ordem geral para o ensino particular, primário e secundário na Província (MIGUEL, 2000, p. 20-35).

Esse regulamento seria revisto e reformulado em 1871, por meio da Lei $\mathrm{n}^{\circ} 290$, de 15 de abril. Essa reforma do Regulamento do ensino era vista como necessária pelo presidente da Província, Venâncio José de Oliveira Lisboa que, em seu Relatório de fevereiro do mesmo ano, afirmava:

[...] ainda a experiência não tinha mostrado o que havia a esperar do bem combinado Regulamento de 1857 [...] quando começou a ser modificado por tantas formas [...], em leis especiaes, e até mesmo em leis de orçamento, que hoje a instrucção pública se acha n'um verdadeiro cahos [...]. Para regularidade, convem que sejam todas as disposições compendiadas em uma só lei e respectivo regulamento (LISBOA, 1871, p. 1-2).

Uma nova reforma no regulamento de ensino seria levada a efeito em 1876, na administração de Lamenha Lins. Para Lilian A. Wachowicz (1984), essas constantes reformulações nas legislações sobre a instrução pública refletem a instabilidade política do período, quando os presidentes 
sucediam-se no cargo após poucos anos de gestão e os regulamentos aprovados por um governo eram criticados pelos sucessores. A situação não era exclusiva do Paraná, mas atingia: "[...] todo o império, aparentemente decorrente da crença de que o Estado, sendo forte e bem intencionado, poderia alterar o quadro da instrução pública, por decretos, leis e regulamentos" (WACHOWICZ, L. A., 1984, p. 82-83).

$\mathrm{Na}$ leitura dos Relatórios, percebe-se a existência de certo otimismo dos Presidentes em relação à instrução pública. Ao tratar desse tema, os textos geralmente iniciam com frases como: "Não há serviço que mais do que este mereça a vossa attenção e patriótica solicitude" (DANTAS FILHO, 1880, p. 34) e "a instrucção, na peleja travada com a ignorância, vae ganhando terreno a olhos vistos" (ABRANCHES, 1875, p. 1). Ao referirem-se dessa forma à educação, os presidentes alinhavam-se a uma visão liberal do Estado brasileiro, onde "a proclamação do valor da instrução pelo Estado, não se dá somente no contexto de interpretação moral, mas também de modernização e crescimento econômico" (WACHOWICZ, L. A., 1984, p. 87).

Entretanto, também era comum em muitos Relatórios o reconhecimento de que o estado da educação na Província não era dos melhores: "A instrucção, por ser um dos mais importantes instrumentos da prosperidade pública, attrahiu logo a minha attenção por seu estado decadente e abaixo toda a crítica" (LISBOA, 1871, p. 1); "É lamentável o estado em que se acha a instrucção pública da província” (MENEZES, 1878, p. 3).

Essa má situação da instrução pública, para além das questões orçamentárias, devia-se, segundo o Relatório do presidente Venâncio Lisboa, em 1872, à "ignorância dos professores, falta de methodo, e obstinação dos paes em não querer mandar os filhos à escola" (LISBOA, 1872, p. 15). Como soluções possíveis a esses problemas, os Relatórios apontavam o fortalecimento da Escola Normal, que prepararia docentes qualificados a exercerem o magistério nas escolas públicas, e a instituição do ensino obrigatório, prevendo-o em lei.

No tocante às escolas dos imigrantes, no contexto da chegada dos primeiros poloneses ao Paraná, destaca-se especialmente a Lei n 310 
de 05 de abril de 1872, que autorizou a concessão de auxílio financeiro, no montante de 2:500\$000 réis, para a construção de uma escola para os imigrantes alemães estabelecidos no rocio de Curitiba (MIGUEL, 2000, p. 155). A respeito dessa doação, o Relatório de 1875, do presidente Abranches, informava: "Essa quantia foi entregue ao presidente da communidade evangélica desta cidade, o qual já prestou contas, tendo a applicado à construcção de um bello e espaçoso edifício" (ABRANCHES, 1875, p. 23).

A Lei $n^{0} 398$ de 11 de abril de 1874, estabelece a criação de uma cadeira de instrução primária promíscua na região do Pilarzinho, servindo também a colônia Abranches, ou seja, atendia desse modo também aos imigrantes poloneses.

Nos Relatórios de Lamenha Lins, a situação das colônias polonesas é descrita, relatando também a questão escolar. Em relação à escola das colônias Abranches e Pilarzinho, o Relatório de 1876 menciona que sua construção já fora iniciada, além da nomeação de um professor interino: o polonês Franz Motsko, que lecionaria provisoriamente em sua própria residência. Na colônia Santa Cândida, uma capela já estava sendo edificada, reconhecendo-se a falta de uma escola. A colônia Órleans já possuía, em um dos lotes, uma casa destinada à escola (LINS, 1876, p. 88-90).

No ano seguinte, Lamenha Lins descreve a existência de uma escola no Pilarzinho, mantida pela Província, e outra na colônia Abranches, na qual lecionava o professor Franz Motsko, mantida pelo Ministério da Agricultura. Segundo o documento, ambas eram muito frequentadas. Em outras colônias, criadas na gestão do próprio Lamenha Lins, como Tomás Coelho e Lamenha, ainda não existiam escolas.

As informações sobre a colônia Órleans, neste Relatório, apresentam-se mais completas. A escola era regida por Jerônimo Durski, bem habilitado para o cargo, e foi frequentada por 31 alunos, no ano anterior. Com o professor da colônia, o governo provincial havia despendido a quantia de $116 \$ 666$ réis, e com utensílios para a escola, $88 \$ 500$ réis, desde a criação da colônia (LINS, 1877). 
A necessidade de escolas nas colônias, mesmo quando identificada pelas autoridades, poderia demorar a ser atendida. Esse é o caso da colônia Tomás Coelho. Em 1879, o presidente Rodrigo Octavio de Oliveira Menezes relata que a colônia carecia urgentemente de duas escolas (MENEZES, 1879, p. 48). No ano seguinte, no Relatório do presidente Dantas Filho, estimava-se em 400 o número de crianças que aguardavam pela construção de uma escola (DANTAS FILHO, 1880, p. 53). Uma escola pública foi criada apenas em $1893^{2}$ e, até esta data: "a colônia procurava solucionar a falta de escola oficial, através de pequenas escolas particulares, onde o colono mais credenciado para tal, e que assim o desejasse, passasse a ministrar aulas de alfabetização, ao menos para parte dos filhos dos colonos" (WACHOWICZ, R. C., 1977, p. 38).

A iniciativa dos imigrantes poloneses em criar escolas para seus filhos, sem esperar providências do governo provincial, pode ser observada em diversas colônias. Essa iniciativa foi mencionada inclusive nos Relatórios: "Na colônia Santa Cândida os colonos contribuem com $500 \$ 000$ para a construcção de uma escola. Tenho a declaração escripta" (CARVALHO, 1882, p. 91).

A criação de escolas pelos próprios imigrantes, fora da esfera do poder público, levou também à criação de um tipo de instituição característica dessas comunidades: as Escolas-Sociedades. Elas são criadas com a fundação de uma Sociedade Recreativa, pela própria comunidade, que:

[...] teria as finalidades de comemorar datas importantes, organizar bailes, recepcionar alguma autoridade que porventura visitasse a colônia e proporcionar à juventude um local onde pudesse divertir-se. Ao mesmo tempo, as programações e as festas realizadas pela Sociedade arrecadariam os fundos necessários para o pagamento

2 WACHOWICZ, R. C., 1977, p. 39. Entretanto, em outra obra (WACHOWICZ, R. C., 2002, p. 22), o mesmo autor identifica 1888 como o ano da abertura da referida escola, porém sem citar a fonte da informação. Opta-se por manter aquela referência no corpo do texto, pois nela o autor cita documentos que confirmam a data da criação da escola e a posse do professor Lourenço Gradowski no cargo. 
de alguma pessoa que pudesse lecionar para as crianças da colônia (WACHOWICZ, R. C., 2002, p. 23).

As Escolas-Sociedades surgem até mesmo nas colônias mais afastadas, levando, em geral, uma existência isolada (WACHOWICZ, R. C., 2002, p. 30).

Em alguns casos, as escolas particulares criadas nas colônias poderiam receber subvenção do governo da Província. Em Tomás Coelho, por exemplo, foram concedidos aos professores Martim Radziazweki e André Polec uma subvenção de $30 \$ 000$ réis mensais, segundo o Relatório de 1886 (TAUNAY, 1886, p. 19).

\section{Considerações Finais}

Durante a existência da Província do Paraná, entre 1853 e 1889, diferentes ocupantes sucederam-se no cargo de presidente, até mesmo alguns que exerciam por pouco tempo sua gestão. Os presidentes elaboravam, ao menos anualmente, Relatórios em que informavam a situação da Província durante suas gestões, abrangendo diversos aspectos. Tais documentos são, atualmente, fontes quase obrigatórias para os pesquisadores interessados em estudar esse período histórico.

A leitura e análise desses documentos devem levar em consideração a forma como esses documentos são construídos. Conforme alertam Gondra e Schueler (2008, p. 56): "[...] a lei não funciona como espelho da realidade, nem a realidade se constitui em reflexo da lei [...]". Embora fundamentados em documentos elaborados por funcionários da administração pública, estatísticas e dados coletados, é possível supor que informações tenham sido deixadas de lado na redação final dos Relatórios, ou sequer tenham chegado ao conhecimento dos presidentes da Província.

Abrangendo apenas a situação das escolas mantidas pelo poder público, os Relatórios não permitem conhecer em maior profundidade outras experiências que se manifestaram nas colônias de imigrantes, como é 
o caso das pequenas escolas particulares, descritas por autores como Ruy C. Wachowicz (2002) e Gluchowski (2005). Escolas estas que preservaram em sua atividade educacional os valores étnicos do grupo polonês.

Apesar de tais lacunas, com a análise dos Relatórios dos Presidentes da Província, é possível verificar alguns investimentos efetuados pelo governo provincial nas áreas da Instrução Pública e Imigração, que recebiam maior ou menor ênfase, conforme o presidente em exercício. A relação entre o discurso dos governantes e as medidas efetivamente tomadas, nessas áreas, pode ser objeto de novas pesquisas para que se somem contribuições de uma melhor compreensão desse período de nossa história.

\section{Referências}

ABRANCHES, F. J. C. de A. Relatório com que o Excellentíssimo Senhor Doutor Frederico José Cardoso de Araújo Abranches abriu a $2^{a}$ sessão da $11^{a}$ legislatura da Assembléa Legislativa Provincial. Curityba: Typographia da Viúva Lopes, 1875.

ARQUIVO PÚBLICO DO PARANÁ. Relatórios de Governo. 2010. Disponível em: <http://www.arquivopublico.pr.gov.br/modules/conteudo/conteudo.php?con teudo=44>. Acesso em 05 nov. 2016.

AZEVEDO, F. de. A cultura brasileira: introdução ao estudo da cultura no Brasil. 6. ed. Rio de Janeiro: Editora UFRJ; Brasília: Editora UnB, 1996.

BURLAMAQUE, P. C. Relatório apresentado à Assembleia Legislativa do Paraná. Curityba: Typographia de Candido Martins Lopes, 1867.

CARVALHO, C. A. de. Relatório apresentado à Assembléa Legislativa do Paraná por ocasião da instalação da $1^{a}$ sessão da $15^{a}$ legislatura no dia $1^{\circ}$ de Outubro de 1882 pelo Presidente da Província o Exm. Sr. Dr. Carlos Augusto de Carvalho. Curityba: Typ. Perseverança, 1882. 
DANTAS FILHO, M. P. de S. Relatório apresentado à Assemblea Legislativa do Paraná no dia 16 de Fevereiro de 1880 pelo Presidente da Província o Exmo. Snr. Dr. Manuel Pinto de Souza Dantas Filho. Curityba: Typographia Perseverança, 1880.

FARIA FILHO, L. M. de. A legislação escolar como fonte para a História da Educação: uma tentativa de interpretação. In: FARIA FILHO, L. M. de. (Org.). Educação, Modernidade e Civilização. Belo Horizonte: Autêntica, 1998. p. 89-125.

GLUCHOWSKI, K. Os poloneses no Brasil: Subsídios para o problema da colonização polonesa no Brasil. Porto Alegre: Rodycz \& Ordakowski, 2005.

GONDRA, J. G.; SCHUELER, A. Educação, poder e sociedade no Império Brasileiro. São Paulo: Cortez, 2008.

KERSTEN, M. S. de A. O Colono-Polaco: A recriação do camponês sob o capital. 1983. 134 f. Dissertação (Mestrado em História Econômica do Brasil) Universidade Federal do Paraná, Curitiba, 1983.

LEÃO, A. E. de. Relatório apresentado ao Exmo. Sr. Presidente Dr. Venâncio José de Oliveira Lisboa pelo Exmo. Sr. Vice-Presidente Dr. Agostinho Ermelino de Leão por ocasião de passar-lhe a administração da Província do Paraná. Curityba: Typographia de Cândido Martins Lopes, 1870.

LINS, A. L. Relatório apresentado à Assembléa Legislativa do Paraná. Curityba: Typ. da Viúva Lopes, 1876.

LINS, A. L. Relatório apresentado à Assembléa Legislativa do Paraná. Curityba: Typ. da Viúva Lopes, 1877.

LISBOA, V. J. de O. Relatório apresentado à Assembleia Legislativa do Paraná na abertura da $2^{a}$ sessão da $9^{a}$ legislatura pelo Exmo. Sr. Presidente Dr. Venâncio José de Oliveira Lisboa no dia 15 de fevereiro de 1871. Curitiyba: Typographia de Candido Martins Lopes, 1871.

LISBOA, V. J. de O. Relatório com que o Exmo. Sr. Presidente Dr. Venâncio José de Oliveira Lisboa abriu a $1^{a}$ sessão da $10^{a}$ legislatura da Assembleia Legislativa Provincial do Paraná no dia 15 de fevereiro de 1872. Curityba: Typpgraphia da Viúva \& Filhos de C. M. Lopes, 1872. 
MENEZES, R. O. de O. Relatório apresentado à Assembléa Legislativa do Paraná pelo Presidente da Província o Excellentíssimo Senhor Dr. Rodrigo Octavio de Oliveira Menezes no dia 9 de abril de 1878. Curityba: Typ. Da Viúva Lopes, 1878.

MENEZES, R. O. de O. Relatório apresentado à Assembléa Legislativa do Paraná pelo Presidente da Província o Excellentíssimo Senhor Dr. Rodrigo Octavio de Oliveira Menezes no dia 31 de março de 1879. Curityba: Typographia Perseverança, 1879.

MIGUEL, M. E. B. A legislação educacional paranaense e a história da educação (1821-1955). In: SEMINÁRIO NACIONAL DE ESTUDOS E PESQUISAS "HISTÓRIA, SOCIEDADE E EDUCAÇÃO NO BRASIL". 4. ed. Campinas: Anais do IV Seminário Nacional de Estudos e Pesquisas "História, Sociedade e Educação no Brasil, 1997. Disponível em: <http://www.histedbr.fe.unicamp.br/acer_ histedbr/seminario/seminario4/trabalhos/trab061.rtf $>$. p. 676-683. Acesso em 03 jul. 2015.

MIGUEL, M. E. B. (Org.). Coletânea da Documentação Educacional Paranaense no Período de 1854 a 1889. Campinas: Autores Associados, 2000.

OBERACKER JR., C. H. A colonização baseada no regime da pequena propriedade agrícola. In: HOLANDA, Sérgio B. de (Org.). História Geral da Civilização Brasileira: O Brasil Monárquico. Rio de Janeiro: Bertrand Brasil, 2004. Tomo 2. Volume 5. Livro segundo, cap. 3, p. 260-288.

SAVIANI, D. História das Ideias Pedagógicas no Brasil. Campinas: Autores Associados, 2007.

SODRÉ, N. W. Síntese de História da Cultura Brasileira. 19. ed. Rio de Janeiro: Bertrand Brasil, 1999.

TAUNAY, A. D’E. Exposição com que o S. Ex. o Sr. Dr. Alfredo D’Escragnolle Taunay passou a administração da Província do Paraná ao Exm ${ }^{\circ}$ Sr. Dr. Joaquim de Almeida Faria Sobrinho $1^{\circ}$ Vice-presidente a 3 de Maio de 1886. Curityba, 1886.

VIEIRA, A. M. D. P. Fontes Digitalizadas na pesquisa em História da Educação. In: CONGRESSO NACIONAL DE EDUCAÇÃO - EDUCERE, 10., 2011. Curitiba. Anais do X Congresso Nacional de Educação - EDUCERE. Curitiba: Champagnat, 2011. 1 CD-Rom. p. 1631-1645. 
WACHOWICZ, L. A. A relação professor-Estado no Paraná tradicional. São Paulo: Cortez; Autores Associados, 1984.

WACHOWICZ, R. C. Tomás Coelho: uma comunidade camponesa. Araucária: Prefeitura Municipal de Araucária, 1977.

WACHOWICZ, R. C. As Escolas da Colonização Polonesa no Brasil. Curitiba: Champagnat, 2002.WACHOWICZ, R. C. História do Paraná. 10. ed. Ponta Grossa: Editora UEPG, 2010.

Recebido: 20/09/2016

Received: 09/20/2016

Aprovado: 20/11/2016

Approved: 11/20/2016 